\title{
Determination of Surface Fluxes Using a Bowen Ratio System
}

\author{
V. C. K. Kakane* and E. K. Agyei \\ Physics Department, University of Ghana, Legon, Ghana \\ *Corresponding author, Email: vckakane@ug.edu.gh
}

\begin{abstract}
Components of the surface fluxes of the energy balance equation were determined using a Campbell Bowen ratio system. The fluxes are obtained by the energy balance Bowen ratio technique, a gradient method that uses vertical gradients of temperature and vapour pressure in combination with point measurements of net radiation and soil heat flow from two sets of soil sensors. The Bowen ratio was measured as the ratio of air temperature and vapour pressure gradients between two fixed heights within $6 \mathrm{~m}$ of the surface. Net radiation $\left(\mathrm{R}_{\mathrm{n}}\right)$ was measured using net radiometers. Soil heat flux $\left(\mathrm{Q}_{\mathrm{g}}\right)$ was measured with ground heat flux plates and the change in energy storage of the layer of soil above the heat flux plates was computed using direct measurements of soil temperature and moisture content. Measurements made every 20 min are stored in the Campbell data logger. Results show most of the net radiation is converted to latent heat when there are more water available for evaporation. Estimates of sensible and latent heat flux have an accuracy of $\pm 10 \%$ of the measured value.
\end{abstract}

\section{Introduction}

Of all the factors that influence the pattern and productivity of rain-fed agriculture in Ghana, the availability of water for crops is by far the most important. The ability to match the pattern of crop water requirement to the availability of water is, therefore, of agronomic and economic importance. Knowledge of the surface energy balance is also of vital importance in advancing the understanding and ability to model land-atmosphere interactions, leading to more reliable weather forecasts. An accurate information on evapotranspiration is an essential element for solving energy and hydrologic cycles of the biosphere as it provides a link between the two cycles.

Short-wave radiation from the sun enters the surface-atmosphere system of the earth and is ultimately returned to space as long-wave radiation (because the earth is cooler than the sun). A basic necessity of this energy interchange is that incoming solar insolation and outgoing radiation be equal in quantity. The following equations can be used to mathematically model net short-wave radiation balance, net long-wave radiation balance, and net radiation balance for the earth's surface at a single location or for the whole globe for any temporal period:

$$
\begin{aligned}
& \mathrm{K}^{*}=(\mathrm{K}+\mathrm{k})(1-\alpha) \\
& \mathrm{L}^{*}=(\mathrm{LD}-\mathrm{LU}) \\
& \mathrm{R}_{\mathrm{n}}=\mathrm{K}^{*}-\mathrm{L}^{*}
\end{aligned}
$$

where $\mathrm{R}_{\mathrm{n}}$ is surface net radiation, $\mathrm{K}^{*}$ is surface net short-wave radiation, $\mathrm{K}$ is surface direct short-wave, $\mathrm{k}$ is diffused short-wave radiation at the surface, $\alpha$ is the albedo of surface, $\mathrm{L}^{*}$ is net long-wave radiation at the surface, LD is atmospheric long-wave radiation directed to the earth's surface, and LU is long-wave radiation lost from the earth's surface.

The net radiation is the amount of energy available to do work at the surface of the earth as it is converted into heat. The redistribution of this energy across the earth's surface is accomplished primarily through three processes. These are first, sensible heat flux, $Q_{h}$, which is the process where heat is transferred from the Earth's surface to the atmosphere by conduction and convection. Secondly, latent heat flux, $Q_{e}$, moves energy when solid and liquid water are converted into vapour. Finally 


\section{West Africa Journal of Applied Ecology (WAJAE) -ISSN: 0855-4307 \\ Volume 9 (Jan - Jun 2006) \\ www.wajae.org}

ground heat flux, $Q_{g}$, is the transfer of sensible heat in the soil towards the surface or away from the surface. The following equation des-cribes the partitioning of heat energy at the earth's surface.

$$
\mathrm{R}_{\mathrm{n}}=\mathrm{Q}_{\mathrm{e}}+\mathrm{Q}_{\mathrm{h}}+\mathrm{Q}_{\mathrm{g}}
$$

The units for the terms in the equation (2) are watts per meter squared $\left(\mathrm{Wm}^{-2}\right)$.

Measurements of latent $\left(\mathrm{Q}_{\mathrm{e}}\right)$ and sensible $\left(\mathrm{Q}_{\mathrm{h}}\right)$ heat flux densities in the atmospheric boundary layer are useful for understanding processes in agriculture and meteorology and also for management applications. Some of the application processes include calibrating and validating crop and water balance models and remote sensing assessments of crop status (Fritschen \& van Bavel, 1962; Dugas et al.,1991).

Several methods exist for $\mathrm{Q}_{\mathrm{e}}$ and $\mathrm{Q}_{\mathrm{h}}$ measurements (Dyer, 1974). measurements. Some of these are lysimeters, water balance, gas exchange with small and large chambers, micrometeorological and remote sensing methods. Each of these has its own assump-tions, and spatial and temporal measurement scales, complexity and expense. The micro-meteorological methods are eddy correlation and Energy Balance Bowen Ratio. The eddy correlation method measures $Q_{e}$ and $Q_{h}$ directly by correlating fluctuations of vertical wind speed with fluctuations of temperature and vapour density, respectively (Swinbank, 1951, Dugas et al., 1991).

The Energy Balance Bowen Ratio (EBBR) system is a ground-based system using in situ sensors to estimate the vertical fluxes of sensible and latent heat at the local surface. The Bowen ratio-energy balance has often been used with very high accuracy (Ashktorab et al., 1989; Nkemdirim \& Haley, 1973; Malek \& Bingham, 1993; Jegede, 2002).

The Bowen ratio, b (Bowen, 1926), is defined as the ratio of the energy available for sensible heating to energy available for latent heating. It is given by:

$\beta=\frac{\mathrm{Q}_{\mathrm{h}}}{\mathrm{Q}_{\mathrm{e}}}=\gamma \frac{\Delta \mathrm{T}}{\Delta \mathrm{e}}$

with

$\gamma=\frac{\mathrm{PC}_{\mathrm{p}}}{\varepsilon \mathrm{L}_{\mathrm{v}}}$

where $\gamma$ is called the psychrometric constant, $\mathrm{P}$ is the atmospheric pressure, $\mathrm{C}_{\mathrm{p}}$ is the specific heat of air at constant pressure, $\mathrm{L}_{\mathrm{v}}$ is the latent heat of vaporization of water, $\varepsilon$ is the ratio of the molecular weight of water vapor $\left(\mathrm{M}_{\mathrm{w}}\right)$ to the molecular weight of air $\left(\mathrm{M}_{\mathrm{a}}\right), \mathrm{T}$ is the temperature, and $e$ is the vapor pressure. Hence, $\Delta \mathrm{T}$ and $\Delta \mathrm{e}$ are the tempe-rature and vapor pressure gradients respectively between the two heights of measurement.

The Bowen ratio is measured as the ratio of the gradients of temperature and vapor pressure across two fixed heights above the surface. All fluxes are positive downward. The Bowen ratio system is applied under the assumption that the turbulent transfer coefficients for sensible heat and water vapor are equal (Dyer, 1974; Ashktorab et al., 1989). 


\section{West Africa Journal of Applied Ecology (WAJAE) -ISSN: 0855-4307 \\ Volume 9 (Jan - Jun 2006) \\ www.wajae.org}

The ground heat flux at the surface is made up of two components. These are the measured flux across a fixed depth and the energy stored in the layer above the heat flux plates. This is calculated using the relation:

$$
\mathrm{Q}_{\mathrm{g}}=\mathrm{FX}+\mathrm{d} * \mathrm{~B}_{\mathrm{D}} *\left(\mathrm{C}_{\mathrm{s}}+\mathrm{W} * \mathrm{C}_{\mathrm{w}}\right) \frac{\Delta \mathrm{T}}{\Delta \mathrm{t}}
$$

where FX is the heat flux measured across a reference depth $\mathrm{d}, \mathrm{B}_{\mathrm{D}}$ is the soil bulk density, $\mathrm{C}_{\mathrm{S}}$ is the specific heat of dry soil, $\mathrm{C}_{\mathrm{w}}$ is the specific heat of water, $\mathrm{W}$ is the soil water content on mass basis ( $\mathrm{kg}$ $\mathrm{H}_{2} \mathrm{O} / \mathrm{kg}$-soil), and $\Delta \mathrm{T}_{\mathrm{S}}$ is the change in the soil temperature in the time interval $\Delta \mathrm{t}$.

From equations 2 and 3(a) above, the sensible heat and latent heat fluxes are determined from:

$$
\begin{aligned}
& \mathrm{Q}_{\mathrm{e}}=\frac{\mathrm{R}_{\mathrm{n}}-\mathrm{Q}_{\mathrm{g}}}{1+\beta} \\
& \mathrm{Q}_{\mathrm{h}}=\frac{\mathrm{R}_{\mathrm{n}}-\mathrm{Q}_{\mathrm{g}}}{1+\frac{1}{\beta}}=\beta \mathrm{Q}_{\mathrm{e}}
\end{aligned}
$$

\section{Study areas}

\section{Materials and methods}

During the period November 1993-April 1996, two locations were studied. The first is the University of Ghana Department of Crop Science Experimental Farm, Legon (39.6 N5 $^{\circ}$, 11.6 W0 ${ }^{\circ}$ ). Measurements were taken over short grass November 1993 to September 1994 and June to July 1995.

The second is at Dawhenya rice irrigation project site from March to April 1996. The farmland is irrigated with water from a dammed river. It is about $40 \mathrm{~km}$ from Accra. It is also grassland interspersed with shrubs and small trees with the water in the background (Fig. 1). 


\section{West Africa Journal of Applied Ecology (WAJAE) -ISSN: 0855-4307 \\ Volume 9 (Jan - Jun 2006) \\ www.wajae.org}

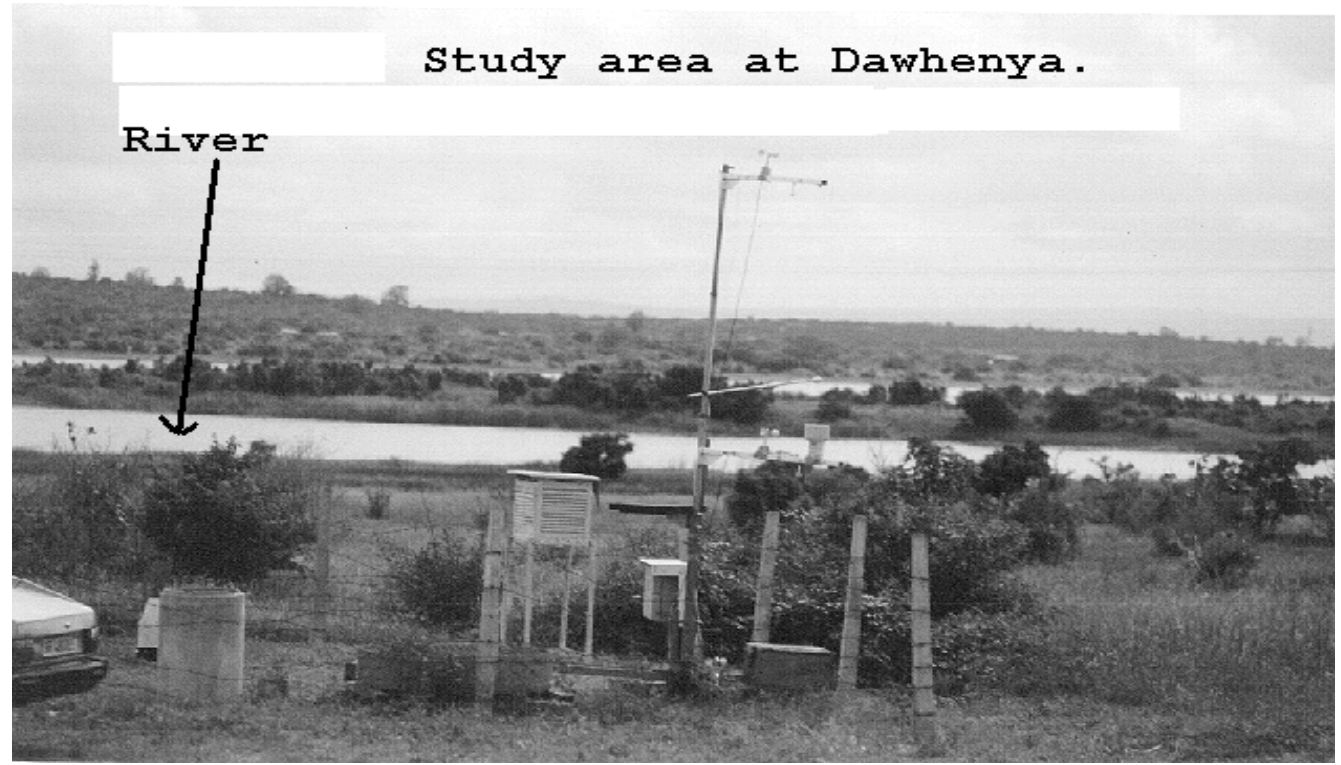

\section{Equipment and measurements}

Fig. 1. Study area at Dawhenya

The Bowen ratio setup, shown in Fig. 2, is manufactured by Campbell Scientific Instruments. It consists of a set of sensors together with logging and control equipment. Sensors used for air temperatures are either chromel-constantan or copper-constantan thermocouples. The fine wire thermocouples and air intakes are located on the horizontal bars on the mast. A net radiometer was used to measure the net radiation. It was usually mounted right at the top of the mast or sometimes on a smaller mast about $2 \mathrm{~m}$ away from the main mast and at $2 \mathrm{~m}$ above surface of short grass.

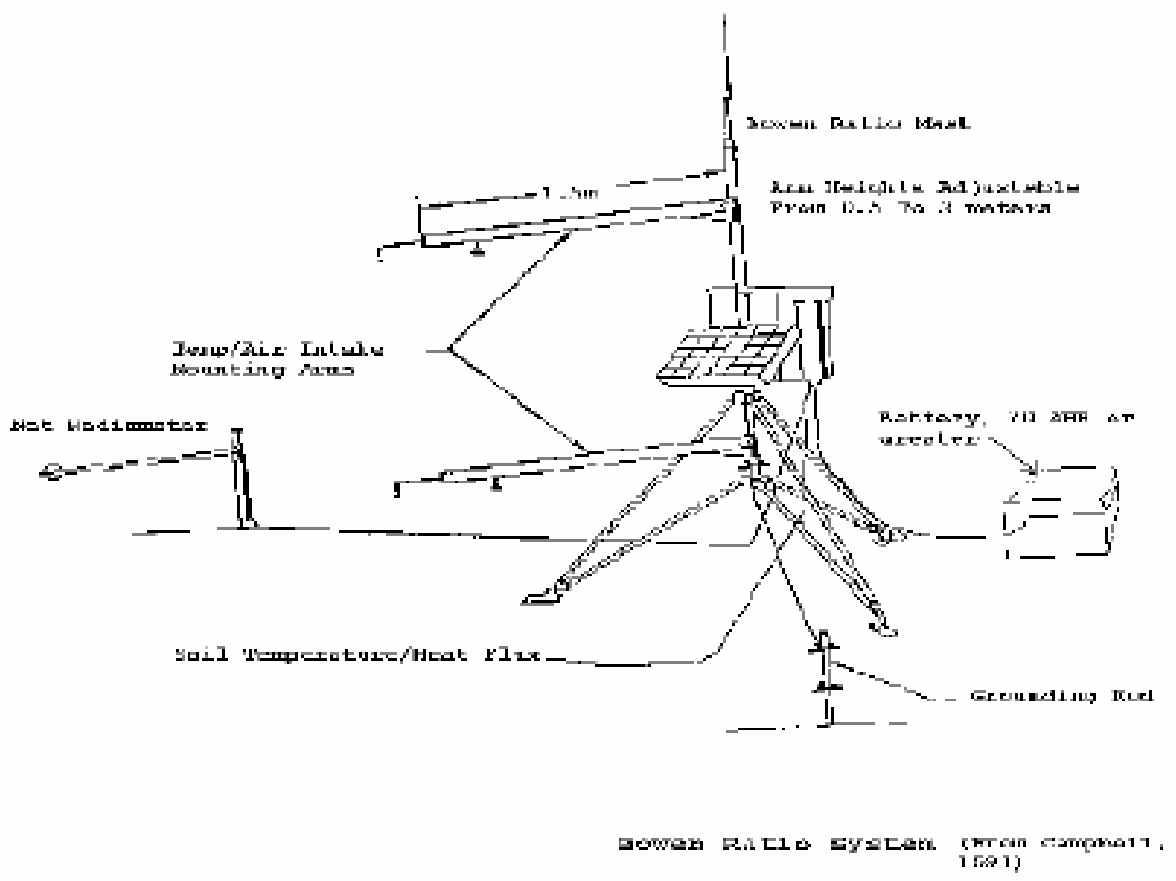

Fig. 2. Bowen Ratio system (From Campbell, 1991)

Volume 9 (Jan - Jun 2006)

Page 4 of 9 


\section{West Africa Journal of Applied Ecology (WAJAE) -ISSN: 0855-4307 \\ Volume 9 (Jan - Jun 2006) \\ www.wajae.org}

Vapour pressure at the two levels was measured with a single cooled mirror dew point hygrometer. Thermopile heat flux plates are used to measure the soil heat flux. The plates are buried at a depth of 8 $\mathrm{cm}$ and within a radius of $2 \mathrm{~m}$ of the mast. Thermocouples are placed $2 \mathrm{~cm}$ and $6 \mathrm{~cm}$, respectively, above the heat flux plates to measure soil temperature. Details of sensors are described in the Campbell Handbook (1991). All data are transferred to the data logger located in the back of the solar panel.

Other measurements made are soil moisture content and the soil bulk density determined once a week. The soils were collected using gravimetric rings and the samples dried in an oven.

\section{Results and discussion}

Twenty minute means of all measurements are shown in the Fig. 3-5. Each figure shows typical diurnal fluxes in a) and b) and the mean fluxes are shown in c). The Bowen ratio represents the sharing of the residual energy between sensible heat transfer to the atmosphere and latent heat. When the Bowen ratio approaches zero, then almost all the energy available is used in evapotranspiration. This implies moisture is unrestricted in its supply. High positive values of the ratio show much of the energy appears as sensible heat and low evapotran-spiration. The surface fluxes are shown for some days and then the mean for a period of 5-7 days. The driving net radiation follows fluctuations. The perturbation is due to clouds. All other fluxes show similar perturbation as the net radiation, and also showed positive values between $0600 \mathrm{~h}$ and $1800 \mathrm{~h}$ and negative values, otherwise.
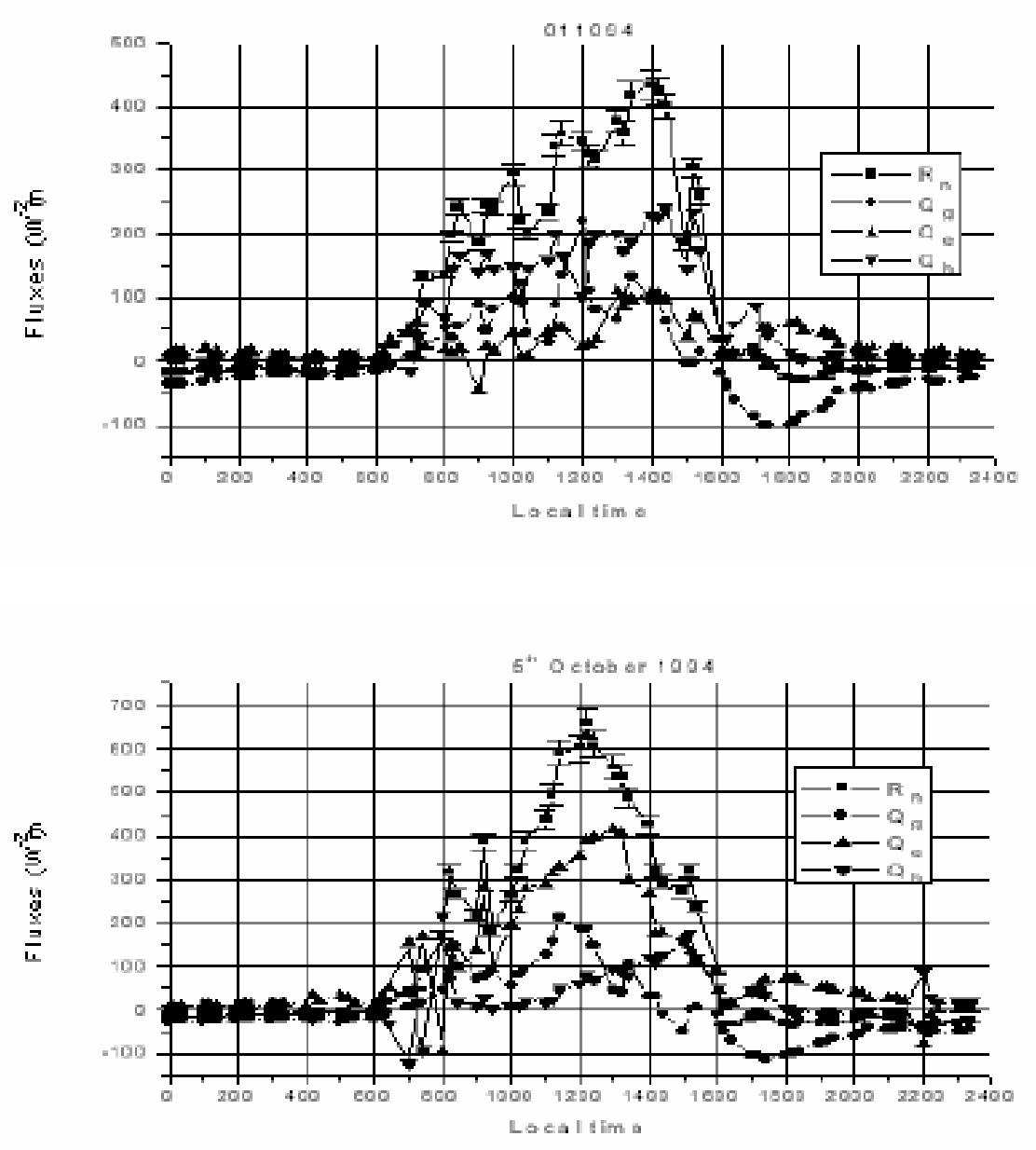

Volume 9 (Jan - Jun 2006)

Page 5 of 9 
West Africa Journal of Applied Ecology (WAJAE) -ISSN: 0855-4307

Volume 9 (Jan - Jun 2006)

www.wajae.org

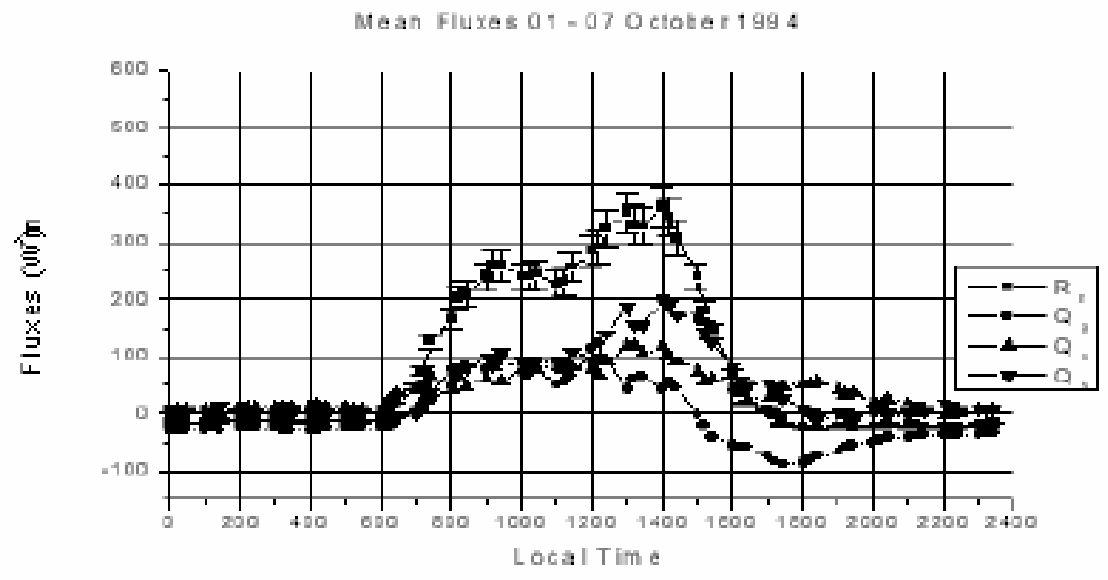

Fig. 3. Fluxes for October 1994
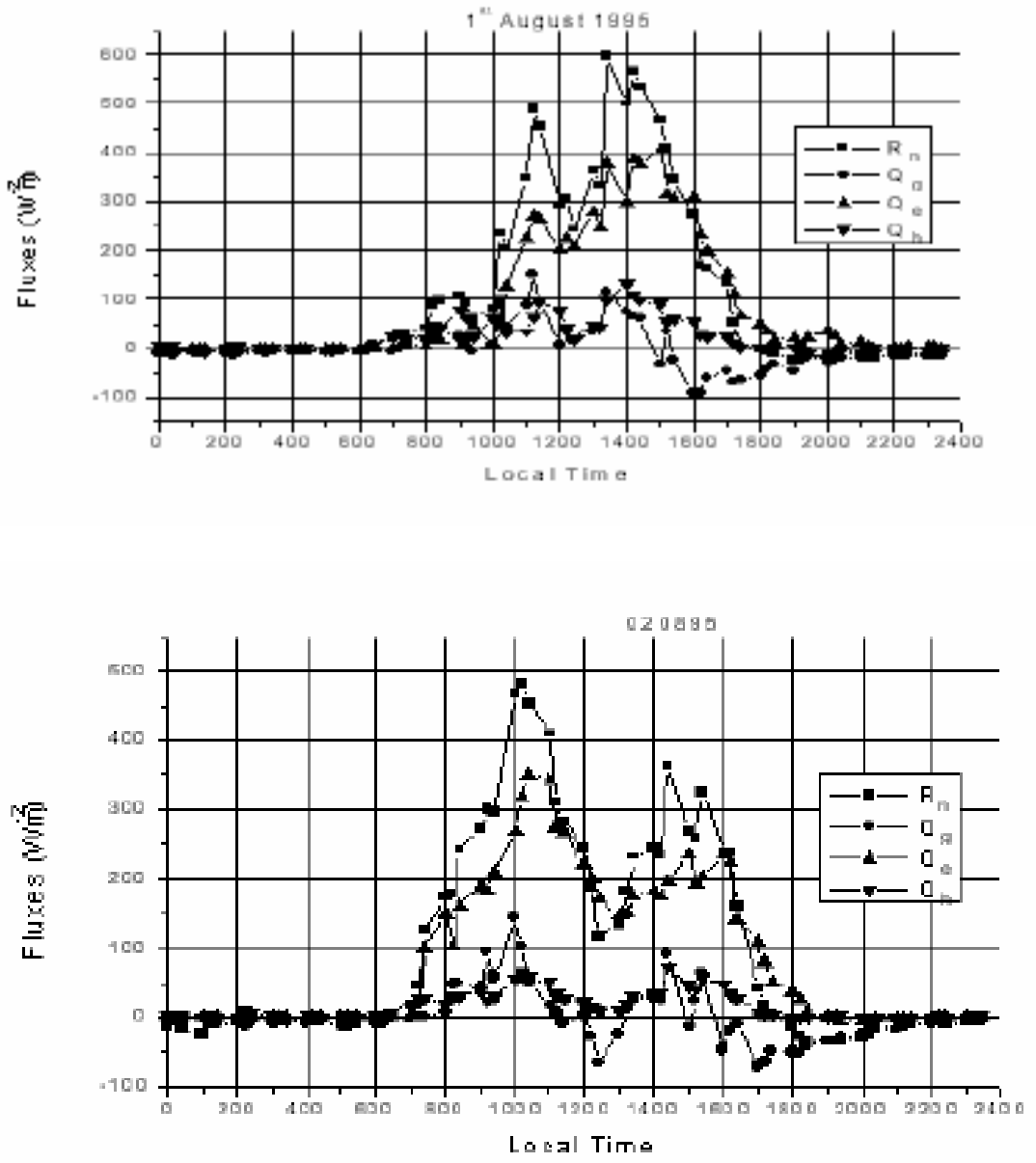

Volume 9 (Jan - Jun 2006)

Page 6 of 9 
West Africa Journal of Applied Ecology (WAJAE) -ISSN: 0855-4307

Volume 9 (Jan - Jun 2006)

www.wajae.org

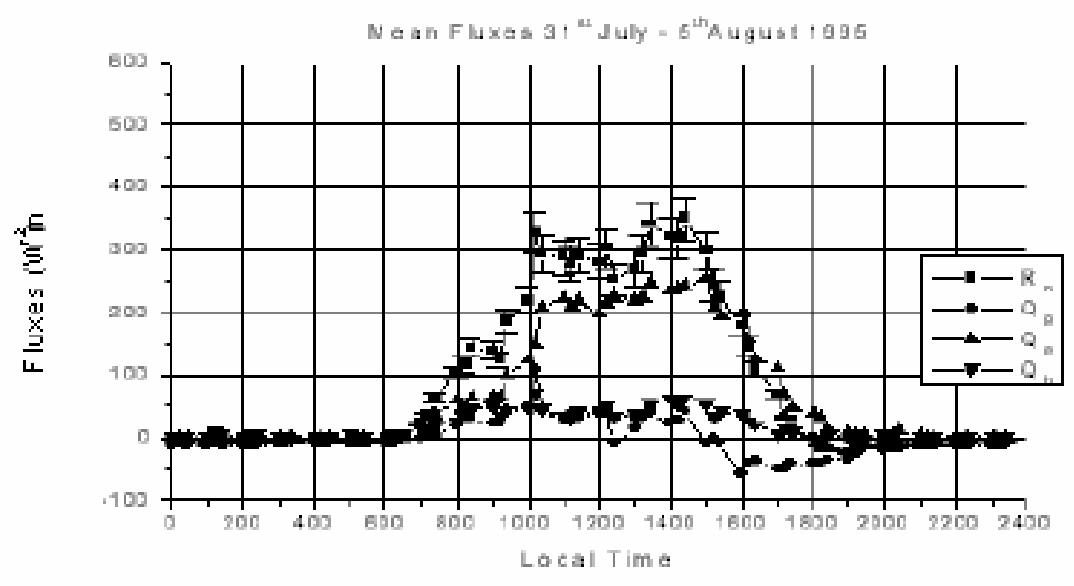

Fig. 4. Fluxes for August 1995
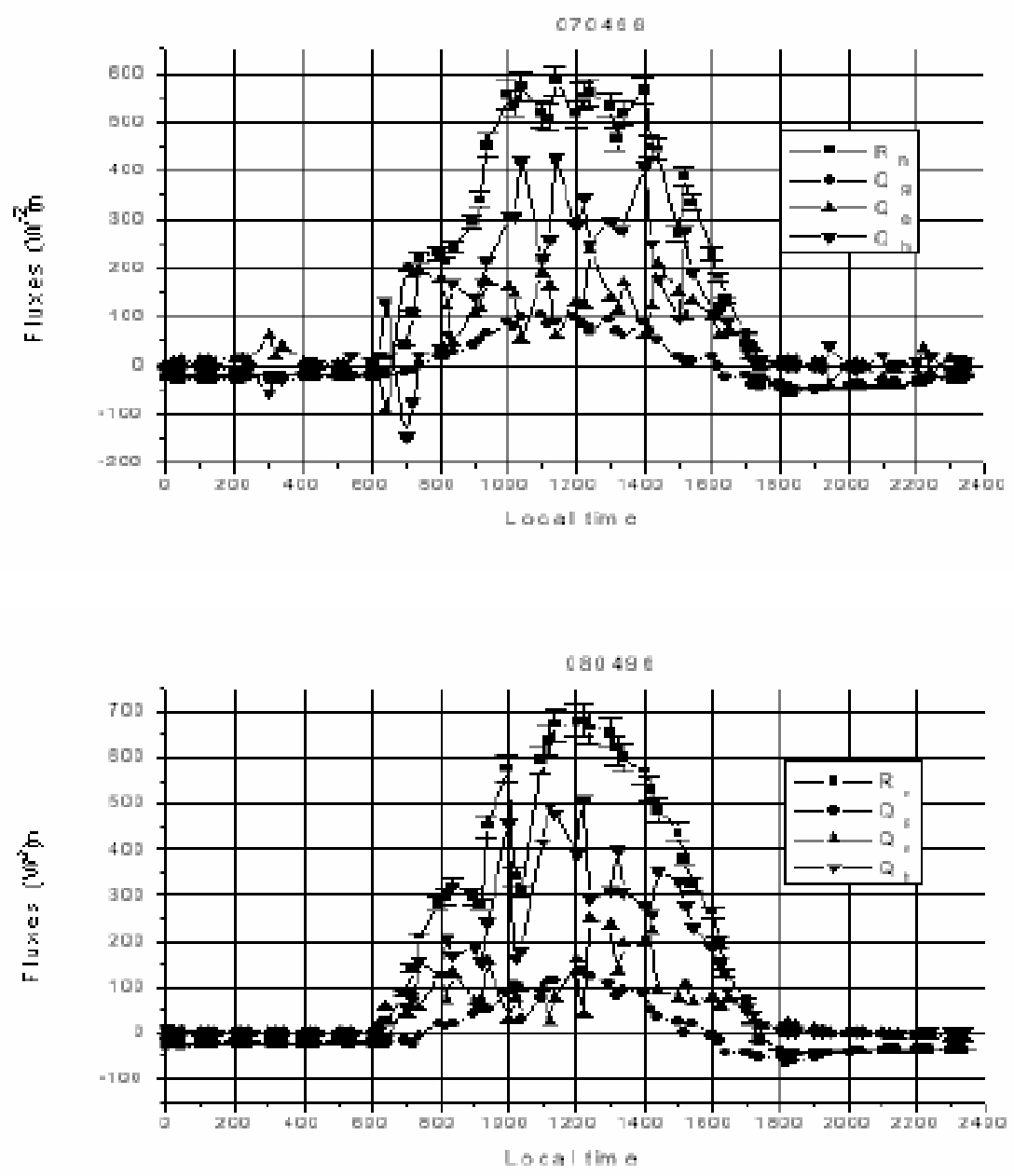

Volume 9 (Jan - Jun 2006)

Page 7 of 9 


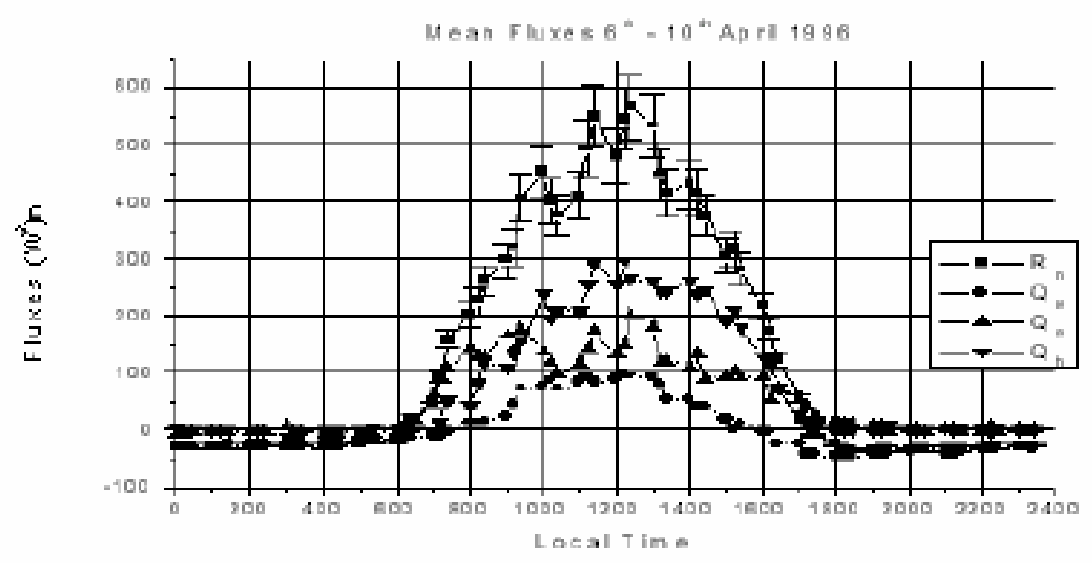

Fig. 5. Fluxes for April 1996

Most days in October 1994, the net radiation was converted to sensible heat. This is due to the dry conditions that prevailed at the time and energy was used in heating the air. Mean net radiation is about $400 \mathrm{Wm}^{-2}$. Sensible heat is predominant in the afternoon from $1400 \mathrm{~h}$. For October latent heat flux exceeded sensible heat for most days. Mean maximum net radiation is about $350 \mathrm{Wm}^{-2}$ and sensible heat flux is very low about $50 \mathrm{Wm}^{-2}$. The mean evaporation rate is about $8.8 \mathrm{~mm} /$ day. August 1995 data were taken over grown corn and showed more latent heat flux than sensible heat flux. There was more water available for evaporation, because of the rain in the earlier months and also transpiration from the corn leaves.

Data for April 1996 are from the Dawhenya irrigation area with the dam in the background. Net radiation was high with mean around $600 \mathrm{Wm}^{-2}$. Latent heat flux was slightly higher than sensible flux in the early morning till $0800 \mathrm{~h}$. After this the sensible heat flux gets higher for the rest of the day. April marks the beginning of the end of the dry season and the beginning of the rains, hence this trend.

\section{Conclusion}

Results have been presented for surface fluxes at certain periods measured in two locations. These results show a lot of fluctuation on the Bowen ratio values and hence on the latent heat and sensible heat fluxes. These fluctuations were mainly due to clouds passing. Days for which latent heat flux appear greater than sensible heat flux imply that Bowen ratio is low and, hence, there is water available for evapotranspiration. Periods of high sensible heat flux mean there is not much water available and the surface air gets heated. In this case the Bowen ratio is high. The values for these fluxes depend a lot on the atmospheric stability and will need to be taken into account. In this case one cannot assume equality of the turbulent transfer coefficients for sensible heat and water vapor.

\section{Acknowledgment}

The authors want to thank the Institute of Geography, University of Copenhagen, for the Bowen ratio equipment. Their gratitude also goes to all the technicians in Physics Department, University of Ghana, for their help in installing the equipment and running it.

\section{References}

Ashktorab H., Pruitt W. O., Paw U. K. T. and George W. V. (1989). Energy balance determination close to the soil surface using a micro-Bowen ratio system. Agric. For. Meteo. 46: 259-274.

Bowen I. S. (1926). The ratio of heat losses by conduction and by evaporation from any water surface. Phys. Rev. 27: 779787. 


\section{West Africa Journal of Applied Ecology (WAJAE) -ISSN: 0855-4307}

Volume 9 (Jan - Jun 2006)

www.wajae.org

Campbell Scientific Ltd. (1991). Bowen Ratio System Instruction Manual. Leicester, UK.

Dugas W. A., Fritschen L. J., Gay L. W., Held A. A., Matthias A. D., Reicosky D. C. , Steduto P. and Steiner J. L. (1991). Bowen ratio, eddy correlation, and portable chamber measurements of sensible and latent heat flux over irrigated spring wheat. Agric. For. Meteo. 56: 1-20.

Dyer A. J. and Hicks B. B. (1970). Flux-gradient relationships in the constant flux layer. Q. J. Roy. Meteo. Soc. 96: 715-721.

Dyer A. J. (1974). A review of flux-profile relationships. Boundary Layer Meteo. 7: 363-372.

Fritschen L. J. and van Bavel C. H. M. (1962). Energy balance components of evaporating surfaces in arid lands. J. Geophys. Res. 67: 5179-5185.

Jegede O. O. (July, 2002). Observations of daytime surface energy balance in cloudy tropical conditions at Ile-Ife, Nigeria. MAUSAM 53 No. 3, pp. 359-366.

Malek E. and Bingham G. E. (1993). Comparison of the Bowen ratio-energy balance and the water balance methods for the measurement of evapotranspiration. J. Hydrol. 146: 209-220.

Nkemdirim L. C. and Haley P. F. (1973). An evaluation of grassland evapotranspiration. Agric. Meteo. 11: 373-383.

Swinbank W. C. (1951). The measurement of vertical transfer of heat and water vapor by eddies in the lower atmosphere. $J$. Meteo. 8: 135-145. 